6-25-2010

\title{
The Vital Role of Social Workers in Community Partnerships: The Alliance for Gay, Lesbian, Bisexual, Transgender and Questioning Youth
}

Michael P. Dentato

Loyola University Chicago, School of Social Work, mdentato@luc.edu

Shelley L. Craig

The Factor-Inwentash Faculty of Social Work, University of Toronto

Mark S. Smith

Barry University, School of Social Work

Follow this and additional works at: https://ecommons.luc.edu/socialwork_facpubs

Part of the Civic and Community Engagement Commons, Gender and Sexuality Commons, and the Social Work Commons

Author Manuscript

This is a pre-publication author manuscript of the final, published article.

\section{Recommended Citation}

Dentato, M.P., Craig, S.L. \& Smith, M.S. (2010). The vital role of social workers in community partnerships for GLBTQ youth. The Child and Adolescent Social Work Journal, 27(5), 323-334. Springer Netherlands, doi:10.1007/s10560-010-0210-0.

This Article is brought to you for free and open access by the Faculty Publications and Other Works by Department at Loyola eCommons. It has been accepted for inclusion in Social Work: School of Social Work Faculty Publications and Other Works by an authorized administrator of Loyola eCommons. For more information, please contact ecommons@luc.edu.

\section{cc) (i) $\ominus$}

This work is licensed under a Creative Commons Attribution-Noncommercial-No Derivative Works 3.0 License. (C) Springer Science+Business Media, LLC 2010 
The Vital Role of Social Workers in Community Partnerships: The Alliance for Gay, Lesbian, Bisexual, Transgender and Questioning Youth 


\begin{abstract}
The account of The Alliance for Gay, Lesbian, Bisexual, Transgender, and Questioning (GLBTQ) Youth formation offers a model for developing community-based partnerships. Based in a major urban area, this university-community collaboration was spearheaded by social workers who were responsible for its original conceptualization, for generating community support, and for eventual staffing, administration, direct service provision, and program evaluation design. This article presents the strategic development and evolution of this community-based service partnership, highlighting the roles of schools of social work, academics, and social work students in concert with community funders, practitioners and youth, in responding to the needs of a vulnerable population.
\end{abstract}

Key words: GLBTQ youth, sexual orientation, community-based partnerships, empowerment, participatory action research. 


\section{Introduction}

A rich history of collaboration exists between community and university-based social workers in the conceptualization, development, and administration of service partnerships. As means for establishing these partnerships, participatory action research is recognized as a preferred methodology for gathering necessary data about community needs, and the utilization of the empowerment perspective is seen as a complementary lens for guiding practice. Participatory action research involves a collaborative process that attends to the engagement of, and reflective dialogues concerning, ideas and viewpoint that have been excluded or privileged in traditional research processes (Guishard, 2009), thus suggesting empowerment as a preferred practice approach. Additionally, such collaborations offer a venue through which academics and social work researchers can influence practitioners' understanding of and willingness to use evidenced based practice (Bellamy, Blesdsoe, Mullen, et al. 2008).

Social workers have historically worked within communities as practitioners, researchers, and advocates for policy change serving vulnerable and oppressed populations: this has, by necessity, involved efforts to develop partnerships among organizations. In order to best meet the identified needs of groups of individuals and oppressed communities, social workers often have to first mobilize, sustain, and stabilize various groups in order to accurately access micro, mezzo, and macro level strengths. Such collaborations are vital to sharing assets, building organizational infrastructure, raising visibility, and developing individual and community-level resilience. Community partnerships comprised of mostly non-profit and public organizations are often created to address complex health and human services needs (Ferguson, 2004). Such partnerships or coalitions are based on the premise that leveraging resources and sharing information can 
enable participating organizations to strengthen their capacities to serve, while improving community health (Provan, et al. 2005).

Community-based partnerships have gained social capital due to the fact that collaboratively, service users and providers can exert significant influence on service and practice standards, often making inroads in a power-saturated field. Thus, fostering alliances with other service users and providers is advantageous (Houston, 2002). Such an approach is considered a way to efficiently deliver services, engage in community planning, encourage disparate providers to work together, and build capacity (Agranoff, 2003). However, because this type of capital is best maximized when it is collectivized or pooled, it must be utilized strategically.

For social workers engaged in developing community-based collaborations, the empowerment perspective can be most useful as an important conceptual foundation. Historically, empowerment-based social work has influenced public institutions, voluntary organizations, proprietary sites, sectarian institutions, secular agencies, unions, corporations, and private practices (Simon, 1994). Similarly, participatory action research has emerged as an important approach in helping social workers gather trustworthy data that is sensitive to the lived experiences of community residents. The fundamental importance of participatory action research methods and the use of an empowerment perspective will be examined with regard to implications for social work practice and building community-based partnerships.

\section{The Vital Role of Social Workers}

Social workers pursue social change adhering to the tenets of social justice, particularly with and on behalf of vulnerable and oppressed individuals and groups of people (NASW Code of Ethics, 2008). In the same regard, there are multiple roles for social workers to become 
engaged in community-based partnerships, from direct practice (i.e. mental health counseling) to program development, creating policy change, and seeking diversified sources of funding to sustain partnership infrastructure. In order to promote competence in assuming these multiple roles, it is vital that undergraduate and graduate social work students be placed in field internships within such organizations involved in community-based partnerships. Social work undergraduate and graduate programs would do well by offering such learning experiences to demonstrate the skills needed for collaborative efforts in program design, implementation, and expansion, funding and development strategies, as well as program evaluation, research and design (Merzel, 2007).

Additionally, social workers would benefit from ongoing training and professional development on how to tune into and contend with potential barriers in their work with client systems. These barriers may present as actual or perceived interference with client networks and may be the result of fractured supportive systems, or systems that have lost effectiveness due to becoming fossilized and irrelevant. Conflict can also occur when social workers harbor private definitions of their purpose, means, or criteria for determining successful outcomes (Simon, 1994) that do not align with those of the community or constituent organizations. Such interference will likely cause friction and dysfunction between the social worker and community collaborators while undermining the critical long-term development of community-based partnerships.

As underscored by Freire (1993) a true commitment to individuals and the larger community involves the transformation of the reality by which oppression occurs. His theory of transformative action is predicated upon affording vulnerable or oppressed individuals, communities, and organizations a fundamental role throughout the process. In essence, social 
workers must challenge fatalistic ideas, such as assuming that change is impossible or that people are incapable of knowing what is best for them (Houston, 2002), and remain steadfast in their commitment to including vulnerable populations in the program design, implementation, and research efforts within community-based partnerships. Lastly, a key role of social workers involves ensuring open access to needed information, services, and resources along with equality of opportunity and meaningful participation in decision making for all people (NASW Code of Ethics, 2008).

\section{The Empowerment Perspective}

Solomon (1976) introduced the concept of "empowerment" in social work as the process by which people increase power on the personal, interpersonal, political, and economic levels in order to take action to gain more control over the conditions of their lives (Boehm \& Staples, 2004). The empowerment perspective offers a clear practice lens through which the multiple positive implications of participatory action research and the development of community-based partnerships can be conceptually linked. An empowerment perspective helps individuals and groups overcome social barriers to self-fulfillment within existing social structures, thus rejecting the transformational aims of radical and critical theory and the emancipatory aims of feminist and anti-discrimination theory (Payne, 2005). Much of the philosophical origins of the social work movement can be found through an examination of the term 'empowerment' and the empowerment perspective, which has had a direct impact on the social, political, socioeconomic, and other aspects of work with vulnerable populations. From an empowerment perspective, the key to rectifying inequitable life conditions is the inclusion of those who are excluded from the social process so that they can contribute to the building of political, economic, and social 
structures which are more participatory and inclusive in nature (Hossen, 2005). However, this a complicated task, as multiple factors and challenges are involved.

In empowerment-based social work with organizations and communities, collaboration closely resembles the "alliance" between social worker and client. This working alliance hinges upon three elements which include: a) a shared sense of urgency concerning the problems confronting the client; b) a conjoint commitment to problem solving in as democratic a manner as possible; and c) a shared emphasis initiated by the worker on the common humanity of all, despite what may be marked distinctions in social class, race, life chances, and education (Reynolds, 1951; Freedberg, 1989; Simon 1994). These three elements of empowerment-based social work are clearly demonstrated in the case example of The Alliance for GLBTQ Youth. We will further explore the three facets of this framework after a discussion about participatory action research.

From an empowerment stance, the perspectives of practitioner and researcher can be unified - so that research methodologies and approaches better fit the realities of practice rather than artificially dismembering practice in order to fit outmoded and incongruent models or research (Pieper, 1985). A self-identity commonly held by contemporary social workers involved in empowerment work is that of the facilitator - one who helps forge pathways to greater power and personal agency for clients, members, and constituents (Simon, 1994). As a process, empowerment is associated with situations in which individuals and groups are moving from relative powerlessness to increased power - for example, participating in decisions that affect their vital interests when previously such participation was denied or made unavailable (Boehm \& Staples, 2004). 


\section{Participatory Action Research}

Participatory Action Research (PAR) has been championed by social workers interested in developing accurate knowledge about marginalized populations because of its attention to the nature of relationships occurring 'inside' the research process, as well as its focus on contributing to the social good, community well-being, and social justice (Cochran, Marshall, Garcia-Downing, et al., 2008). Furthermore, PAR encourages introspection and examination of the social interdependencies among researchers and those researched (Boser, 2006; Maiter, et al., 2008). Social workers involved in The Alliance for GLBTQ Youth worked in such an interdependent fashion while holding a firm commitment to the key social work tenets of empowerment, reciprocity, self-determination, mutuality, and consensus building throughout the process of developing the community-based partnership. Such a "reciprocal dialogue," in which an individual researcher and community participants communicate as equals has the potential to help avoid or resolve certain ethical problems in research (Trimble \& Fisher, 2006; YassourBorochowitz, 2004; Maiter, et al. 2008).

Further, the manner by which a social worker negotiates, engages, and facilitates research with the community at the center of the project is key to producing strong outcomes. The style of engagement helps determine the quality and nature of the relationship, the depth of the emergent data, and the extent to which the researcher is regarded as a trustworthy ally capable of sharing and articulating any aspect of participants' world views (Genat, 2009). Ultimately, the sine qua non of authentic collaboration is ongoing reciprocity of effort, ideas, resources, and, most important, respect (Simon, 1994). This third element of the empowerment perspective utilizing a "shared dialogue" underscores the "shared emphasis initiated by the worker on the common

humanity of all" (Reynolds, 1951; Freedberg, 1989; Simon 1994). Based on a professional code 
of ethics, standards, principles and values, social workers are most likely to exemplify the attributes necessary for building community-based partnerships, while enhancing the delivery of services and creating research opportunities, all while advocating for vulnerable populations.

In sum, the choice of research paradigm becomes important (Burrell \& Morgan, 1979; Hassard \& Keleman, 2002; Walji, 2009) when establishing and developing community-based partnerships. Ideally, collaborative community-based research should highlight reciprocity, contribute quality and richness in feedback, and inform, clarify, and contribute to the enhancement of all involved (Deetz, 1996; Walji, 2009). These outcomes are characteristic of both PAR processes and empowerment goals. Such a collaborative, collective, and comprehensive process clearly illustrates the fundamental role of multiple partners and the key influence of social workers in developing community-based partnerships. The linkage between the role of social workers, the empowerment perspective, and PAR will be further examined in the following case example.

\section{The Alliance for GLBTQ Youth}

Typically, community agencies that provide services that specifically respond to the needs of gay, lesbian, bisexual, transgender and questioning (GLBTQ) youth must also engage in ongoing advocacy (Morrow, 2004). Social workers in these agencies who provide services to GLBTQ youth often must utilize their advocacy skills, especially in working with other traditional and non-traditional service providers so as to better ensure that an adequate continuum of care is provided. By training and working alongside personnel within these agencies, social workers can improve service delivery to the GLBTQ community (Morrow \& Messinger, 2006). The Alliance for GLBTQ Youth is a community-based service partnership that emerged from the advocacy efforts of social workers in one metropolitan area who regularly 
experienced such gaps in service and were frustrated by the absence of care continuity. The collaboration stemmed from the grass roots level intervention of community members, funders, and community-based organizations seeking the stabilization and expansion of services for GLBTQ youth. The tasks of mobilizing community members, engaging in PAR to assess community needs, developing a collaborative strategy for initiating a new partnership, as well as the staffing, administration, and evaluation of service outcomes, were all handled by social workers coming together from community-based organizations, local university schools of social work, faculty members, and students.

For the social workers and various community partners involved in the initial discussions and planning, the overall mission of the service partnership immediately became clear. The mission was to create and implement a continuum of care for GLBTQ youth, their families, and communities. The first element of an empowerment perspective - "a shared sense of urgency concerning the problems" - clearly describes this initial period of community organization (Reynolds, 1951, Freedberg, 1989; Simon, 1994). The primary course of action was to bring the various service providers together on a monthly basis, build bridges, and start the planning process. Such service providers included organizations that focused on school-based education and prevention programs, mental health counseling, crisis intervention, HIV/AIDS services, alcohol and substance abuse programs, recreational and social activities, among others.

Despite great promise and good intentions, developing community alliances can be fraught with challenges, as community collaborations are difficult to initiate and even more challenging to sustain (Berberet, 2006). One early challenge for the Alliance for GLBTQ Youth was the initial positive response by administrators of agencies and organizations engaged in the project and the subsequent failure to ultimately delegate the direct work to program staff. The 
commitment and "buy-in" to the project varied by organization; consequently, social workers found that leveraging resources and utilizing political influence were key factors in unifying cohesion among individual group members as well as among the larger group as a whole. Other challenges involved either external constraints, such as lack of funding, or involved internal factors, such as conflicts arising between individuals. Many of the internal conflicts were motivated by competition among the non-profit organizations with long histories of vying with each other for funding, clients, and community status (Libby \& Austin, 2002). Social workers had to examine issues of trust and assist partnering organizations with long-standing positive and negative relationships in either re-establishing trust through the collaborative process or address fractures and dysfunction along the way.

The Alliance for GLBTQ Youth experienced considerable challenge with attempting to link unique and idiosyncratic organizations with a wide range of infrastructure development. These agencies had varied levels of financial support, histories of failed attempts at collaboration, service duplication, and a "limited" number of GLBTQ youth that they were reaching through service provision. Ironically, the social workers found that the potential appeared quite unlimited for collaboration and expansion of services for underserved GLBTQ youth clients. To address these concerns, open and frank dialogues were initiated between Alliance program staff and the community-based partners on topics as varied as the need for increased service provision, meeting contractual requirements, or the likelihood of funding cuts. Quite often these intense dialogues took great time, multiple attempts, and effective negotiation among partners through several phone calls, face-to-face meetings, emails, and the use of clear communication and critical consensus building skills, so that ultimately a decision was formed underscoring the mission of the partnership as the guiding principle shaping present and future 
actions.

In order to develop trust, especially among marginalized communities, there are moments in which the credibility of the project and the researchers are tested (Maiter, et al., 2008), and these conversations occasionally led to contentious crossroads. Inherent throughout these critical moments was the instrumental role of social workers as brokers, bridge-builders, and negotiators, navigating delicate conversations with the youth, service providers, funders and Alliance staff members through a multitude of varied modes of communication and/or meetings. Building consensus and creating an open dialogue and process proved instrumental for mid-course evaluation and adjustments to the project, and emphasized the importance of empowerment, active participation, relationship-building and effective collaboration. This second instrumental element of the empowerment perspective - consensus building - underscores the need for " $\mathrm{a}$ conjoint commitment to problem solving in as democratic a manner" as possible (Reynolds, 1951, Freedberg, 1989; Simon, 1994).

The social workers initiating the community-based partnership engaged in a twelve-month planning grant initiative focused on establishing the partnership and developing organizational components such as generating a mission statement and governance plan. The research process included a broad-based youth survey, convening multiple focus groups with GLBTQ youth and providers, conducting local, state, and national key informant interviews, on-site visits to exemplar and model programs, and undertaking a comprehensive literature review. This extensive participatory research process culminated in a multi-year, multi-million dollar implementation grant provided by a local community funding source. The initial development of community cohesion utilized the elements of empowerment practice through fostering shared responsibility. 
The decision-making process throughout the planning and implementation processes occurred in an open manner at monthly partnership meetings, through various partnership committee telephone conference calls, mass emails sent to all partners, and through the dissemination of messages from administrators and partners when dialoguing with their staff, youth, and the greater community. Such participatory decision-making has been found to be a key ingredient of success of such community partnerships (Mizrahi \& Rosenthal, 2001). Several formal and informal strategies were utilized by the leadership of the Alliance for GLBTQ Youth that included: a) adherence to the consensus decision-making model; b) the use of ad hoc committees; and c) formal documentation of process. Early on in the formation of the Alliance, the governance committee recommended the use of a consensus model as the primary decisionmaking model. This meant that decisions were made through full participant agreement. In the instances when everyone was not in full consensus, a dialogue was initiated and persisted until everyone was in complete agreement. For a few decisions there appeared to be degrees of agreement and disagreement and the strong board leadership took the time to ensure that nuances were articulated. Reservations expressed by members did not necessarily mean that consensus was thwarted. Instead the concerns became part of the charge to staff members or committees while formalizing action plans. For some challenging decisions, particularly those involving funding, differences of opinion were frequently found. The board leadership then formed ad hoc committees consisting of those who had expressed the most concern. This committee was charged with reporting back a plan of action at the next partnership meeting.

Finally, in a strategy designed to nurture the equitable decision-making model of the community partnership, the leadership insisted on formal documentation of all decisions. This was done through extremely detailed minutes as well as formal written policies, bylaws, and 
memoranda of understanding. All written documentation was circulated during the monthly meetings and copies were kept in a binder at the office. This allowed for open access to the decision-making strategies by the community partnership as well as by any interested member of the community. Such participatory approaches to decision making can be viewed as positive because decisions are more likely to be grounded in the relevant issues because stakeholders are making them (Dotterweich, 2006) and can lead to enhanced levels of trust and result in future collaborations. Such an example of the empowerment perspective through the decision-making process might be important to further assess, as it has been shown to be essential to the goals and outcomes of shared governance models (Anthony, 2004; Erickson, Hamilton, Jones \& Ditomassi, 2003; Larkin, et al., 2008).

Consumer and community input, including direction and feedback from all the various interested constituencies such as youth, agency staff, administrators, as well as with staff from the multiple funding sources in the project was fundamental to the success of this partnership as well. Croft and Beresford (1994), argue that a participative and empowering approach is valuable because people want and have a right to be involved in decisions and actions taken in relation to them. One early success from utilizing this approach stemmed from the invitation of several community-based funders to the table to provide input, direction, and feedback in the planning and implementation processes. Their participation in the early development of the partnership ultimately led to an invitation from a local chapter of The United Way for an application for funding to cover one specific service area of the developing partnership.

Constituent involvement reflects the democratic value base of social work, increases accountability, makes for more efficient services, and helps to achieve social work goals. It also helps to challenge institutionalized discrimination by broadening the role of a community in such 
a project. These feedback loops were created through the relationships established and maintained by the social work researchers and practitioners who facilitated the initial dialogue and meetings. Community stakeholders were able to voice their opinions and give their responses in a series of twenty-four community meetings that incorporated a range of six to thirty-one participants. During these meetings the governance and other leadership documents were created and cohesion was further fostered. As articulated by Croft and Beresford (1994), the community stakeholders' view of participatory practice involved four elements, which included: a) empowerment, which involved challenging oppression and making it possible for people to take charge of matters which affect them; b) control for people in defining their own needs and having a say in decision making and planning; c) equipping people with personal resources to claim power by developing their confidence, self-esteem, assertiveness, expectations, knowledge and skills; and d) organizing their agencies to be open to participation.

An interesting note about the definition of community with this project was with regard to the addition of the use of "Q" in the acronym for The Alliance for GLBTQ Youth. Throughout the design of a youth survey about various aspects of their lives and behaviors, lengthy discussions about inclusiveness took place among adults and youth alike. While some youth reported that they remained uncommitted to specific self-identities based on the accepted social definitions for the continuum of sexual orientations and felt more comfortable with a broader set of choices than the typical "gay, lesbian, bisexual, or transgender" terms widely used, adults also felt strongly about offering such a myriad of options and believed "GLBT" was sufficiently inclusive. However, it also became clear that a significant number of youth were more comfortable being defined "loosely" with regard to their sexual orientation and appreciated the decision to use "Q" for those still questioning their identity. This adolescent self-identification 
aligns with Savin-William's perspective articulated in The New Gay Teenager (2005) regarding youth and their objection to being "neatly categorized." Therefore, with a commitment for empowerment of youth regarding self-disclosure and identification, all providers, staff, and youth alike eventually agreed that the use of the "Q" should be included in community definitions.

Ultimately, the various service providers acted as key stakeholders in the service partnership, motivated in part by opportunities for receiving funding for services (i.e. individual, family, and group mental health counseling, prevention education, recreational and social events), but also participating through consensus-based decision processes at monthly board meetings, involvement in the selection/interview process for new Alliance staff, and active engagement in strategic planning processes. Fundamentally, establishing partnership relationships promoted mutual respect, increased communication and collaboration, and helped to achieve organizational objectives (Batson, 2004; Larkin, et al. 2008).

Additionally, the social workers who acted as integral members of this collaboration, whether serving on the board, as the project director, staff members, or as research consultants, all felt strongly about the need to closely align The Alliance for GLBTQ Youth with local universities. This was essential not only to strengthen the potential for research opportunities and develop undergraduate and graduate field placement opportunities, but also to lend greater credibility to the partnership. Contact was established with the administration of local schools of social work, field placements were established, and ongoing collaborative efforts continue to actively engage additional social work faculty and students with the partnership.

At The Alliance for GLBTQ Youth, agency providers, staff, and most importantly, youth remain vital elements of service provision, program administration, and board leadership. 
Growth of the project remains strong as providers continue to bring additional organizations to the table, and most importantly, new youth into the service continuum of care. This case example vividly describes the key role of social workers in developing community-based partnerships, the use of the empowerment perspective in working with vulnerable and oppressed populations, and the critical involvement of community-based organizations collaborating with universities and social workers while promoting advocacy for vulnerable populations.

\section{Moving Ahead}

In developing and sustaining community-based partnerships, social workers' mediating relationship with vulnerable populations and the organizations that serve them can provide a vital link between grounded research efforts and informed responsive service provision. An objective of social service research is to provide helpful information about the complex and oftentimes illdefined problems practitioners encounter every day (Pieper, 1985). As illustrated throughout this discussion, the empowerment perspective and collaborative processes of PAR can effectively inform the fundamental role of social workers in developing and sustaining community partnerships for vulnerable populations such as GLBTQ youth. More effective partnerships require a foundation of trust among stakeholders, including researchers, administrators, frontline staff, recipients of services, and concerned members of the community (Fantuzzo, McWayne \& Childs, 2006). Furthermore, it may be beneficial to further examine the perceptions, definitions and overall impact of trust among partners in such collaborations through future research and writing.

As community partnerships are being explored within the curricula of other helping professions, it may also be beneficial for schools of social work to explore the integration of such learning opportunities into their BSW and MSW programs (Epstein \& Sanders, 2006). 
Academics may serve as catalysts for community partnerships by suggesting that instead of merely looking to communities for research participants, that universities provide sustainability and longevity to strengthen community partnerships (Milofsky, 2006). Positive actions have been taken by individual professors at various colleges and universities who, independently, designed courses on school, family, and community partnerships or added relevant readings to existing courses in education, sociology, psychology, and social work (Epstein \& Sanders, 2006). Educators may continue to define unique opportunities for academia to partner more strongly with the practice community to strengthen mutual learning opportunities.

As illustrated by the case example of The Alliance for GLBTQ Youth, social workers can provide a vital role in integrating and managing the various methods necessary to build effective community-based partnerships. The Alliance for GLBTQ Youth is a solid example of an evolving partnership, exemplifying the vital role of integrating the interests of community-based organizations, social workers, social work students, and schools of social work in responding to the needs of vulnerable populations. Such an example underscores the full extent and positive impact of utilizing an empowerment perspective inherent in such collaborative efforts, leaving much room for further exploration and development of community-based partnerships among similar populations. 


\section{References}

Agranoff, R. (2003). Leveraging networks: A Guide for public managers working across organizations. Washington, D.C: The Center for the Business of Government.

Anthony, M. K. (2004). Shared governance models: The theory, practice and evidence. The Online Journal of Issues in Nursing, 9(1), 138-153.

Baston, V. (2004). Shared governance in an integrated health care network. Association of Perioperative Registered Nurses Journal, 80(3), 493-518.

Bellamy, J. L., Bledsoe, S. E., Mullen, E. J., Fang, L., \& Manuel, J. I. (2008). Agency-university partnership for evidence-based practice in social work. Journal of Social Work Education, 44(3), 55-75.

Berberet, H. (2006). Putting the pieces together for queer youth: A model of integrated assessment of need and program planning. Child Welfare, 85(2), 361-384.

Boehm, A., \& Staples, L. H. (2004). Empowerment: The point of view of consumers. Families in Society: The Journal of Contemporary Social Services, 85(2), 270-280.

Boser, S. (2006). Ethics and power in community-campus partnerships for research. Action Research, 4, 9-21.

Burrell, G., \& Morgan, G. (1979). Two dimensions: Four paradigms. In G. Burrell \& G. Morgan, (Eds.), Sociological paradigms and organizational analysis (pp. 21-37, 82-87, 395-402, in passum). Ashgate, England: Heinemann.

Cochran, P. A. L., Marshall, C. A., Garcia-Downing, C., Kendall, E., Cook, D., McCubbin, L., \& Gover, R. M. S. (2008). Indigenous ways of knowing: Implications for participatory research and community. American Journal of Public Health, 98, 1, 22-27. 
Croft, S., \& Beresforf, P. (1994). A participatory approach to social work. In C. Hanvey \& T. Philpot (Eds.), Practicing social work, (pp. 49-66). London: Rutledge.

Deetz, S. (1996). Describing differences in approaches to organization science: Rethinking Burrell and Morgan and their legacy. Organizational Science, 7, 191-207.

Dotterweich, J. (2006). Building effective community partnerships for youth development: Lessons learned from ACT for youth. Journal of Public Health Management and Practice, 25, 15-36.

Epstein, J. L., \& Sanders, M. G. (2006). Preparing educators for school-family-community partnerships: Results of a national survey of colleges and universities. Peabody Journal of Education, 81(2), 81-120.

Erickson, J. I., Hamilton, G. A., Jones, D. E. \& Ditomassi, M. (2003). Measuring the impact of collaborative governance: Beyond empowerment. Journal of Nursing Administration, 33(2), 96-104.

Fantuzzo, J., McWayne, C. \& Childs, S. (2006). Scientist-community collaborations: A dynamic tension between rights and responsibilities. In J. E. Trimble \& C. B. Fisher, (Eds.), The handbook of ethical research with ethnocultural populations and communities, (pp. 2749). SAGE: Thousand Oaks, CA.

Ferguson, C. (2004). Governance of collaborations: A case study. Administration in Social Work, $28(2), 1-22$.

Freedberg, S. (1989). Self-determination: Historical perspectives and efforts on current practice. Social Work, 34(1), 33-38.

Freire, P. (1993). Pedagogy of the oppressed: New revised $20^{\text {th }}$ anniversary edition. Continuum: NY. 
Genat, B. (2009). Building emergent situated knowledges in participatory action research. Action Research, 7(1), 101-115.

Guishard, M. (2009). The false paths, the endless labors, the turns now this way and now that: Participatory action research, mutual vulnerability, and the politics of inquiry. Urban Review, 41, 85-105.

Hassard, J., \& Kelemen, M. (2002). Production and consumption in organizational knowledge: The case of the 'paradigms debate'. Organization, 9, 331-355.

Hossen, M. A. (2005). Empowerment-based social work practice: Issues and challenges. The Indian Journal of Social Work, 66(2), 196-210.

Houston, S. (2002). Reflecting on habitus, field, and capital: Towards a culturally sensitive social work. Journal of Social Work, 2(2), 149-167.

Larkin, M. E., Cierpial, C. L., Stack, J. M., Morrison, V. J. \& Griffith, C. A. (2008). Empowerment theory in action: The wisdom of collaborative governance. Online Journal of Issues in Nursing, 13(2), 2-2.

Libby, M., \& Austin, M. (2002). Building a coalition of non-profit agencies to collaborate with a county health and human services agency: The Napa County Behavioral Health Committee of the Napa Coalition of Non-Profits. Administration in Social Work, 26(4), 81-100.

Maiter, S., Simich, L., Jacobson, N., \& Wise, J. (2008). Reciprocity: An ethic for communitybased participatory action research. Action Research, 6(3), 305-325.

Merzel, C. (2007). Developing and sustaining community-academic partnerships: Lessons from downstate New York Healthy Start. Health Promotion Practice,8(4), 375-383. 
Milofsky, C. (2006). The catalyst process: What academics provide to practitioners. Nonprofit Management and Leadership, 16(4), 67-480.

Mizrahi, T., \& Rosenthal, B. B. (2001). Complexities of coalition building: leaders' successes, strategies, struggles and solutions. Social Work, 46(1), 63-78.

Morrow, D. F. (2004). Social work practice with gay, lesbian, bisexual, and transgender adolescents. Families in Society, 85(1), 91-99.

Morrow, D. F., \& Messinger, L. (2006). Sexual orientation and gender expression in social work practice: Working with gay, lesbian, bisexual, and transgender people. New York: Columbia University Press.

National Association of Social Workers. Code of Ethics. Assessed on December 5, 2008 at: http://www.socialworkers.org/pubs/code/code.asp.

Payne, M. (2005). Modern social work theory (3rd ed.). Chicago: Lyceum.

Pieper, M. H. (1985). The future of social work research. Social Work Research \& Abstracts, 21(3), 3-11.

Provan, K. G., Veazie, M. A., Staten, L. K., \& Teufel-Shone, N. I. (2005). The use of network analysis to strengthen community partnerships. Public Administration Review, 65(5), 603-613.

Reynolds, B. C. (1951). Social work and social living. (Reproduced 1975). Bethesda, MD: National Association of Social Workers.

Simon, B. L. (1994). The empowerment tradition in American social work: A history. New York: Columbia University Press. 
Savin-Williams, R. C. (2005). The new gay teenager. Boston: Harvard University Press.

Solomon, B. B. (1976). Black empowerment: Social work in oppressed communities. New York: Columbia University Press.

Trimble, J. E., \& Fisher, C. B. (2006). Our shared journey: Lessons from the past to protect the future. In J. E. Trimble \& C. B. Fisher (Eds.), The handbook of ethical research with ethnocultural populations and communities, (pp. xv-xxix). Thousand Oaks, CA: Sage.

Walji, N. (January 2009). Leadership: An action research approach. AI \& Society, 23(1), 69-84.

Yassour-Borochowitz, D. (2004). Reflections on the researcher-participant relationships and the ethics of dialogue. Ethics \& Behavior, 14(2), 175-186. 